\section{The PASS-model: a model for guiding health-seeking behavior and access to care research}

\author{
Susanna Hausmann-Muela, ${ }^{1}$ \\ Joan Muela Ribera, ${ }^{1,2}$ Elizabeth Toomer, ${ }^{1}$ \\ Koen Peeters Grietens ${ }^{1,3}$ \\ 'Partners for Applied Social Sciences - \\ PASS International, Tessenderlo, \\ Belgium; 'Universitat Rovira i Virgili, \\ Tarragona, Spain; ${ }^{3}$ Institute of Tropical \\ Medicine, Antwerp, Belgium
}

\section{Abstract}

The mobilization of affordable measures and treatments has brought health services and health care tools closer to the poor. This is particularly the case in the context of malaria control and elimination efforts. Still, the other side of delivery is use: the targeted populations have to access and accept these resources. Although the need to better align the delivery and user sides is increasingly recognised, there still is a gap between this awareness and researchers' response to adequately address the community side in a way that actionable results can be achieved. In order to avoid actions based on preconceptions, practical applications should draw from theoretical knowledge. Furthermore, in order to get a total view, such applications should consider the full array of potential factors relevant for access to care or health-seeking behavior (HSB). We believe that one of the reasons why theoretically-based, holistic approaches to HSB and access to care still are scarce is the lack of a hands-on and easy-to-use model that allows the researcher to ask the right questions and to interpret the results. In this article, we present such a model, the PASSmodel for HSB and access to care. Founded on theory, the model facilitates the formulation of questions to cover the broad array of elements that guide HSB and access to care. It is adaptable to different contexts and research questions. The goal is that any researcher interested in situating health behavior in a given social, political, and economic landscape can use this tool for any health condition, in low income as well as high income countries.

\section{Introduction}

Communities are fundamental for the success of implementation of new and already well-established interventions. For malaria, there have been so many innovations community responses and uptake of new tools in the past decades, that this topic is now at the forefront of interest. People have to use the available health services and tools, i.e. they have to access and accept the resources. For a long time, implementers of interventions have recognized that there is a need to investigate health-seeking behavior (HSB) and access to care in order to adapt programs to local contexts. The Steering Committee on Strategic Social, Economic, and Behavioural Research (SEB) working for the UNICEF/UNDP/World Bank/WHO Special Programme for Research and Training in Tropical Diseases (TDR) has been fostering research and training. Their aim is to gain to a better understanding of how socio-behavioral and economic factors affect malaria and other diseases. ${ }^{1,2}$ With regard to this, an extensive body of literature deals with behavioral aspects of malaria prevention and treatment.,3

To get a holistic picture, we need to know what questions to ask and how to interpret the results. These are conceptual as much as methodological challenges and require overcoming disciplinary boundaries. The use of research models facilitates the study of HSB and access to care in relation to current tools and measures like the use of mosquito-nets, access and acceptability of intermittent preventive treatments, adherence to treatment, the use of diagnostic tools, etc. However, the mostly quantitative HSB and access to care approaches tend to focus on a reduced number of factors, often without preparatory exploratory in-depth research. This kind of research is exemplified by knowledge, attitudes, behavior, and practices (KABP) surveys that have been criticized for their reductionist approach. ${ }^{4-6}$

Health and HSB models from social psychology, ${ }^{7,8}$ public health (e.g. the Three Delays Model), ${ }^{9}$ and social sciences (e.g. the Health Care Utilization Model), ${ }^{10}$ and the Ethnographic Decision Tree Modeling ${ }^{11}$ allow for a considerable extension of the determinant factors of KABP and similar studies. The major enhancement is that all these models contain associations of variables that are considered relevant for explaining or predicting HSB. Moreover, they provide conceptual definitions for these variables that are derived from the social and behavioral theory. Of particular interest is the ACCESS model for vulnerable populations, which combines health services, health-seeking and sustainable livelihood approaches. ${ }^{12}$ Such models permit a view of the full array of potential factors relevant for access to care or HSB.

The PASS-model - developed within the PASS International organization (www.passinternational.org) - presents a comprehensive framework for health planners and researchers who are interested in studying HSB and access to care, applicable to malaria and other dis-
Correspondence: Koen Peeters Grietens, Institute of Tropical Medicine, Nationalestraat 155, 2000 Antwerp, Belgium.

Tel. +32.3.247.66.66 - Fax +32.3.216.14.31

E-mail: kpeeters@itg.be

Key words: Health seeking behaviour, malaria, access to care.

Conflict of interests: the authors declare no potential conflict of interests.

Contributions: all the authors contributed equally.

Received for publication: 17 April 2012.

Revision received: 5 December 2012

Accepted for publication: 5 December 2012.

This work is licensed under a Creative Commons Attribution NonCommercial 3.0 License (CC BYNC 3.0).

(C)Copyright S. Hausmann-Muela et al., 2012

Licensee PAGEPress, Italy

Malaria Reports 2012; 2:e3

doi:10.4081/malaria.2012.e3

eases. The origins of the PASS-model go back to a Disease Control Priority Project (DCPP) working paper on health-seeking behavior and the health system response ${ }^{4}$ which provided an overview of HSB and access to care models applicable to malaria and a reflection on its advantages and shortcomings. The idea behind the PASS-model is to thoughtfully select elements from different access and HSB models, and merge them together on theoretical foundations. This model is conceived of as an easy-touse and hands-on tool to develop theory-based hypotheses that cover as many aspects as possible without losing sight of the real aim, i.e. to identify the principal reasons determining HSB and access to care and to produce actionable results.

\section{The PASS-model, an overview of factors and categories}

The PASS-model is built on the backbone of a pathway model, i.e. a model describing the steps of the path that people follow when seeking care. It focuses on the factors involved in each step that hinder or facilitate a prompt treatment and access to care.

The PASS-model (Figure 1) organizes its factors into four main categories: i) illness perception and explanatory models; ii) decision making and social values; iii) access to care and resource seeking; and iv) medical pluralism. Behind the model are worldviews, social structures and values, and medical 
organizations that build the context of healthseeking processes and furnish the different factors at play with specific meaning. In what follows, we will provide an overview of the different categories of the model.

\section{Illness interpretation}

\section{Knowledge of causality}

According to Kleinman, ${ }^{13}$ explanatory models (EMs) represent the notions people hold about an episode of sickness. These models offer explanations for their experience of sickness and treatment and explain people's choices among available therapies and therapists. EMs also explain how people understand the illness etiology, mode of transmission, symptoms, pathophysiology, course of sickness, treatment, side effects of medicines and ways of preventing disease. One of the key elements that guide behavior in HSB studies is knowledge. Usually, knowledge is assessed to establish how far community knowledge exists and/or overlaps with biomedical concepts.

In malaria research, for example, several authors have reported that malaria transmission or the malaria-mosquito link was not clear to a considerable number of people in the communities studied. ${ }^{14,15}$ In other areas, a high percentage of respondents were aware of the way malaria is transmitted, ${ }^{16,17}$ but unclear about other aspects that determine HSB, such as the adverse effects of the medication..$^{18}$ However, the reasons guiding health seeking behavior for malaria tend to be multi-causal rather than mono-causal. Besides mosquitobites, the perceived etiology often includes hot sun, changes in the weather, cold, rains, drinking dirty water and hard work. ${ }^{2,19,20}$

Different perceived causes may simply coexist or interrelate within an EM. Janzen, ${ }^{21}$ for example, showed how viruses and bacteria interact with witchcraft. One of his informants explained how in a healthy body contaminated food would pass through without provoking negative effects, whereas in a bewitched body, the ill-causing agents of the same food would be retained and eventually penetrate into the blood. The merging of different concepts is also made explicit in the local understanding of malaria in south-eastern Tanzania where malaria and witchcraft can be interrelated in illness interpretations. ${ }^{22}$ Among the population, it is common to believe that witchcraft can impede biomedical treatment from working or malaria parasites from being detected in the blood - it is said that witchcraft hides the parasites by putting a veil between the body and the outside.

Two concepts help to understand local illness interpretations: i) the double level of causality, and ii) the existence of folk illnesses.

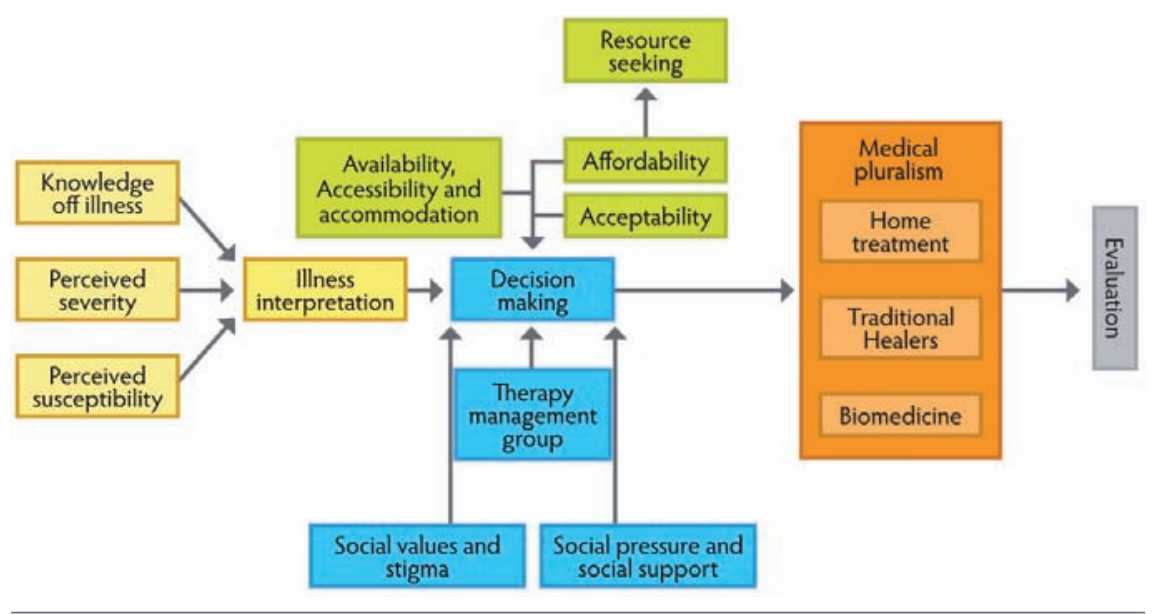

Figure 1. The PASS-model for health-seeking behavior and access to care research.

\section{The double level of causality}

The double level of causality ${ }^{23}$ refers to natural and mystical etiologies that are often interchangeable or linked. It explains much of normative treatment-seeking behavior, as is clear in the case of malaria and witchcraft. For example, a bewitched person who suffers from malaria must seek treatment from a traditional healer who can remove the witchcraft prior to attending the hospital for malaria treatment. Typically, observed treatment sequences with alternating use of traditional and biomedical resources follow a logic of interpreting and re-interpreting illness, using merged concepts from biomedicine and local beliefs in witchcraft. 22,24

\section{Folk illnesses}

Health-seeking behavior studies have been devoting particular attention to folk illnesses and their role in treatment-seeking. ${ }^{25}$ Rubel $e t$ $a{ }^{26}$ defined folk illnesses as syndromes from which members of a particular group claim to suffer and for which their culture provides an etiology, a diagnosis, preventive measures, and regimens of healing, but that do not correspond to existing biomedical diseases. In HSB research for malaria, the best-known examples of folk illnesses are those characterized by convulsions, a sign of cerebral malaria, which in Africa is commonly attributed to a spirit attack. ${ }^{27-29}$ In Tanzania this feared folk illness is called degedege. ${ }^{16,19}$ Because severe manifestations of malaria are often interpreted as other diseases (e.g., degedege), treatment with is not perceived to be appropriate nor efficacious. ${ }^{2}$

Although, in principle, for folk illnesses people tend to seek traditional treatment, EMs are a complex melting pot of different kinds of knowledge. In southeastern Tanzania, for example, degedege for the same people is very commonly both severe malaria and a folk illness attributed to mystical attacks of a big moth. The treatment pattern follows a process of cooling down the body with traditional remedies at home, until the patient can be treated for malaria at the hospital. ${ }^{24,30}$

\section{Knowledge of symptoms}

People can usually mention one or even several symptoms of a disease they are familiar with. However, knowledge of symptoms is not the same as symptom recognition. Even if respondents are able to identify pale skin as a symptom of malaria-related anemia, recognizing it under real life conditions requires some training. ${ }^{31}$ Moreover, illness symptoms (including those of malaria) are often diffuse or unspecific and difficult to interpret (i.e. nausea and headache for pregnant women in malaria endemic areas), and illness courses or treatment outcomes are sometimes unexpected. Facing this uncertainty, people can follow a trial and error search for relief and meaning. ${ }^{32,33}$ Under these circumstances, even good biomedical knowledge of cause, symptoms and treatment would not affect behavior.

\section{Knowledge on preventive measures and treatment}

People use a broad array of measures to prevent certain illnesses. They also use different types of medicine to treat illness, from traditional home remedies to sophisticated biomedical products. These medicines are understood and used (or not used) according to local perceptions. ${ }^{34}$ Knowledge about medical products comes from multiple sources, including health promotion campaigns and media advertisements, booklets, and dyadic communication with family members, friends, knowledgeable persons, shop keepers, traditional and biomedical health practitioners, etc. Research on knowledge about preventive measures and medication can be approached by looking at: i) what people 
do to prevent or treat a specific health problem and why, and ii) what people know (and what they do not know) about a pharmaceutical, a medicinal plant or any other remedy.

At this point, it is important to distinguish between declarative knowledge, i.e. local knowledge about the name, composition, uses, side-effects, the risks of not completing or interrupting the prescribed dosage, etc., and practical knowledge, i.e. when and how to use medical products, dosage, etc. Although sometimes neglected, practical knowledge is a key topic for health promotion. It includes, for example, knowledge on how to collect and prepare medicinal plants, take unpleasant medicines in a safe way (e.g. bitter malaria pills for children), on proper dosages, properly hang a mosquito net, etc.

Like illness interpretations, local perceptions of medication are deeply rooted in culture and may hinder adequate treatment if people are convinced that a certain drug, the way of administration, or the dosage, is too strong or too weak for a particular age or bodily state. For example, injections are often perceived to be stronger than pills (e.g. in Cambodia, personal communication), and people may fear that injections are too strong for small children (as is the case in the Peruvian Amazon, personal communication). A neglected topic in HSB studies is the role of perceived side effects of medication in adherence to treatment. For example, around Iquitos, in the Peruvian Amazon, 70\% of P.vivax malaria patients mentioned that anti-malarial treatment shocked them and produced side-effects. The underlying logic is that the prescribed drugs are hot, which on top of a hot disease (malaria) provoke excessive heat that is bad for the patient's health. ${ }^{18}$

\section{Perceived severity and perceived susceptibility}

Health-seeking behavior is further guided, among other factors, by beliefs or perceptions about the consequences of the disease, depending on: i) the perceived severity of a disease or health problem and its consequences, and ii) perceived susceptibility, or how vulnerable a person considers him/herself to actually contract a certain illness or health problem (see the Health Belief Model) ${ }^{35}$.

\section{Perceived severity}

The perceived severity of disease and beliefs about the aggravation of symptoms are determinants for treatment-seeking behavior. In the case of malaria, Sauerborn ${ }^{36}$ showed how the perception of illness severity changed with seasonality, related both to climatic conditions and workload. Weller and colleagues ${ }^{37}$ found that the perceived severity of an illness, together with economic resources and prior experiences with this illness were the main criteria guiding treatment choice in a Guatemalan community. Similarly, Garro, ${ }^{38}$ working in Pichátaro, Mexico, described perceived severity of the illness as the most relevant criterion determining treatment choice. According to Garro, for illnesses considered serious, treatment costs are of secondary importance, unlike non-severe illnesses where treatment selection primarily depends on the probability of cure and not on costs.

Relevant questions for assessing perceived severity include: i) whether a disease is perceived to be mild or severe; ii) whether people are aware that the disease has severe complications; iii) which symptoms are associated with severity and aggravation of a health problem; iv) and, whether the severe complications of the disease are understood as the same illness or not. For instance, in an endemic area in Kenya, Mwenesi ${ }^{39}$ found that malaria was considered a mild disease. The same applied to diarrhea in Pakistan, which was locally understood as a way of cleansing the body. ${ }^{25}$ In the case of severe malaria, vomiting is often perceived to be a sign of relief rather than of aggravation of the disease $\mathrm{e}^{24,40}$ (Iquitos, Peru, personal communication).

\section{Perceived susceptibility}

While perceived severity is a key factor for understanding treatment-seeking behavior and delay, perceived susceptibility (whether people perceive themselves to be at risk/susceptible) is especially relevant for prevention and has important implications for preventive HSB.

Commonly, risk perception of malaria tends to be linked to perceived mosquito density, which often manifests in a decrease of preventive measures when they are still necessary. ${ }^{41-43}$

Relevant questions for assessing perceived susceptibility are: i) who is perceived to be more susceptible to contract a disease; ii) who is perceived to be more susceptible to die or to have complications from a disease; iii) where do people perceive they are more likely to contract a disease; iv) when (time of the day, period of the year) do they perceive this; v) and, under what conditions (e.g. when it rains, in cold weather, due to collective sin, during war) do people perceive themselves to be more susceptible to contract a disease.

\section{Knowledge and practice}

One of the most debated questions in health promotion is how far knowledge actually determines practice. It is common to assume, implicitly or explicitly, that changing knowledge entails behavior change. Hence, a vast body of literature concludes with recommending the education of people about causes, symptoms and treatment. However, it is also widely recognized that improving knowledge with well-designed IEC campaigns, for example, does not necessarily lead to improved health behavior. ${ }^{44}$

This is because apart from the complexities of knowledge, there are a range of other factors relevant for HSB, such as the unavailability of health facilities, the lack of drugs, the lack of money to pay for preventive or treatment costs etc.

\section{Decision-making and social values}

Mistakenly, certain health-care seeking models are based solely on the individual. Yet, as people are part of households, families and communities, ${ }^{45,46}$ illness is a social matter.

Therefore, health-seeking itineraries should be seen in the context of culture and social organization, including ideologies of gender, kinship, class and so on. While a detailed examination of all the factors involved in decision-making is not possible here, we devote some attention to the most important structural ones: social networks, social values and stigma, social pressure and previous experiences.

\section{Social networks and the Therapy Management Group}

Decisions on health and treatment can be a complex kinship issue ${ }^{47}$ and the set of individuals who take charge of therapy management with or on behalf of the sufferer, called the therapy management group (TMG), ${ }^{21,48}$ are key to understanding HSB.

According to Janzen ${ }^{21}$ the TMG exercises a brokerage function between the sufferer and the specialist as various maternal and/or paternal kinsmen, and occasionally their friends and associates, rally for the purpose of providing information, lending moral support, making decisions, and arranging details of therapeutic consultation.

In order to understand the relevance of the TMG for health-care seeking in a given context, we need to understand: i) the social structure of the group, i.e. who participates in the TMG and in what social position; and ii) the role of the individuals within this group, i.e. who gives advice, who decides what, who pays, who accompanies the patient, who seeks information, who takes care of the patient, etc.

Within the TMG structure and functioning there are certain key factors such as gender roles and relations, age and authority, social position, etc. The most obvious example of the importance of gender is found in caring, which is widely understood as a woman's role. Paradoxically, while in many African communities mothers are the main caretakers and therefore the ones who first notice their children's signs of illness, it is the father who usually controls economic resources and consequently decides about treatment. ${ }^{39}$ According to Mwenesi, ${ }^{39}$ health programs should therefore not only target mothers but also fathers in 
awareness rising for disease control.

However, it is important to distinguish between normative (in line with social norms) and normal (actual) behavior: in Tanzania, for example, decision making and cash control are normatively in men's hands, but for natural illnesses like malaria it is normally the mother who decides and pays for the treatment. ${ }^{49}$

Moreover, the TMG is a changing institution. The number of people involved, and the weight, intensity and commitment of the TMG depends on many factors, including age and sex of the ill person; type of family (e.g. extended, nuclear, single parents); social position and social capital; and severity, length and costs of the illness. For example, the TMG is usually bigger, more active and committed for mystical diseases, i.e. ancestors' punishment or witchcraft, that afflict the family as a whole, than for natural (or simple) illnesses, which affect just the ill person..$^{50}$

\section{Social values and stigma}

Like any kind of behavior, health-seeking is founded on social values. Social values tacitly define what particular behavior is expected from a woman or a man, being rich or poor, when young or later in life, and in any given situation. Social prestige, shame, social discredit or stigma are related to whether one's actions have abided by expectations or violated them. The question is how and to what extent social values hinder or facilitate health seeking.

For example, owning a mosquito net can be a sign of wealth or responsibility; and caring for the family a source of prestige for men (the responsible father). On the contrary, fear of being labeled as a bad mother and shame because one's child looks dirty or ill, too thin, etc. can act as an obstacle for health-care seeking, ${ }^{51}$ relevant, for example, for the use of intermittent preventive malaria treatments in infants (Gabon, communication of the authors). Similarly, since health centers are public spaces where some socially discrediting ${ }^{52}$ and stigmatizing conditions can be aired, fear of losing face and social exclusion are often powerful barriers for accessing care. ${ }^{53,54}$ This is an important problem for public health, affecting, for example, access to antenatal care for pregnant teenagers and use of intermittent preventive malaria treatments in pregnant women. ${ }^{52}$

A neglected question in HSB studies is: when resources are scarce, who has priority for using preventive measures or receiving treatment in the household? Social values related to gender and age are, again, relevant. Priorities are established according to these social values and pragmatic reasoning. For example, among the Luo in Kenya, parents sleep on a bed with a mattress and have priority access to the only bed net in the house, if one exists. The rest of the family sleeps on the floor on shared papyrus reed mats. When asked to explain this custom, several mothers said that there is no money to buy extra bed nets, and children can endure lack of sleep due to mosquito nuisance. It is the adults who have to struggle to provide for them and therefore need to sleep well. ${ }^{55}$ In this example, project priorities for disease control (children under five and pregnant women) clash with Luo's criteria for the use of preventive measures (i.e. bed nets).

\section{Social pressure and social support}

Social pressure is a powerful tool to maintain people's behavior within the norms and values of social groups and subgroups. It is important to distinguish between social pressure (i.e. the one exercised by neighbors, family members or peers) and official pressure (i.e. legal and other forms of pressure exercised by authorities). For example, for vaccines, official pressure can be high while social pressure may be low or non-existent. The strength of social pressure depends on a variety of factors, for instance whether the problem or health activity is perceived to be a community matter or a private issue, or the degree of social cohesion.

However, the mere perception of social pressure may influence behavior ${ }^{56}$ as referred to in social psychology as the subjective norm, i.e. the belief whether other relevant persons will approve one's behavior, plus the personal motivation to fulfill the expectations of others. ${ }^{57}$

For instance, unlike with HIV/AIDS, tuberculosis or witchcraft-related health problems, malaria is a socially acceptable disease, with low social pressure to seek treatment or to pay for treatment. ${ }^{3}$ In southeastern Tanzania, for example, although a good father is the one who cares for his children - and paying for his child's treatment is a father's responsibility - social pressure to observe this obligation is very low. ${ }^{49,58}$

\section{Previous experience}

Previous experience with health resources makes people develop ideas on how a product or a system works, and they acquire a sense of familiarity with these resources. Moreover, previous experience contributes to satisfaction/dissatisfaction and influences perceived quality of care, waiting time, costs, etc. It also generates expectations and gives a frame of reference for the comparison between different preventive tools and/or health providers. In addition, previous experience with a disease helps build up cognitive schemas on disease manifestations, which are essential for symptom recognition. According to Weller, ${ }^{37}$ in a Guatemalan community prior experiences with a disease were one of the three key factors for treatment choice.

\section{Access to care and resource seeking}

It has become popular among researchers to use different categories grouping key factors for HSB. The best known examples are known as the five As: availability, accessibility, acceptability, accommodation and affordability of health resources. ${ }^{59}$ The advantage of this categorization is the easy identification of key potential barriers for adequate treatment. Research on the access determinants requires an understanding of both the provider and the demand sides.

\section{Availability, accessibility and accommodation}

Availability of health resources within a political region and/or geographical area, and accessibility to these resources by the population, and accommodation between the health services and people's needs are the basic determinants for access to health care. Availability is mainly a health policy issue, at local, national and international level, while accessibility is mainly socio-structural.

Research on availability and accessibility focuses on topics such as: i) geographical location of health resources, including hospitals of different levels, health centers and pharmacies; ii) availability of diagnostic tools; ii) availability of health personnel, including Village Health Workers and other community workers; iv) availability of pharmaceutical and other treatment resources; v) availability of preventive measures, e.g. mosquito nets; vi) availability of traditional and informal health care providers; vii) distance from home to health resources; viii) distance from fields, forest or working place to health resources; ix) mobility factors, e.g. state of the roads, safety, transport options (i.e. bus, car, bicycle, etc. from the demand side; and the presence of an emergency system - radio, ambulance and other vehicles - from the health sector); $\mathrm{x}$ ) health facilities opening hours; and xi) waiting time at the health center and people's work load.

\section{Acceptability}

Acceptability is related to the social and cultural distance between the provider and the demand sides. Research on acceptability of health care resources is frequently reduced to satisfaction studies. Although people's satisfaction is pivotal for acceptability, there are other factors at play: i) clear communication and respect; ii) confidentiality and privacy; iii) perceived quality of care; iv) perceived benefits, v) perceived inconveniences and, vi) perceived risks of preventive measures and treatment.

The health personnel-client dynamic can be in itself a barrier for health care. Major complaints concerning health personnel behavior include poor explanations on dosage and treatment regimens; rudeness on the part of health personnel; and a blaming-the-victim mentali- 
ty. ${ }^{60,61}$ However, such health personnel responses should be contenxtualized and one must first look at the low salaries, and poor working conditions, of health personnel and more broadly at institutional cultures that tend to reproduce inequitable power relations and related abuse.

Acceptability of health services and products is a complex issue. Health resources generally have direct perceived benefits and inconveniences; however complementary or secondary perceived benefits (i.e. not related to the main health issue, such as attending an expensive clinic which confers prestige), and risks (expected problems or difficulties), are also influential in health services acceptability. An example of these acceptability categories with regard to bed nets as a malaria control measure $^{41}$ is shown in Table 1.

\section{Affordability}

Disease related costs cannot only hinder prompt treatment seeking but can also have a serious negative impact on people's economic resources. ${ }^{62}$ To facilitate research, it is necessary to distinguish between direct costs (medical or non-medical), indirect costs and intangible costs.

Direct costs are costs linked with seeking and receiving treatment and preventive measures and can either stem from medical treatment (direct medical costs), i.e. hospital costs, health centers' and practitioners' fees, medicine, etc., or from other expenses that are not medical such as transportation costs, meals and accommodation (direct non-medical costs). ${ }^{62}$

Indirect costs refer to productivity loss or earnings loss due to the morbidity time during which the patient and caretaker(s) stop or reduce productive activities while seeking or receiving treatment.

Incalculable or intangible costs are those costs for certain consequences of illness that cannot be expressed or directly converted into monetary values. These include some of the illnesses' long-term consequences such as abandonment of schooling, disability and deformity, social exclusion, and psychosocial factors.

\section{Resource seeking and coping strategies}

When patients or caretakers do not have cash to cope with disease costs, they usually employ a series of strategies to find the required resources or to deal with the consequences of the lack of those resources. Resource seeking is often an itinerary, with different steps, which includes asking relatives and neighbors for cash, selling assets, borrowing, etc. This process, sometimes described as a race, may be shorter or longer depending on the social networks, on particular conjunctures, e.g. availability of money or casual work, on the illness course, etc. and is closely linked to social vulnerability. ${ }^{49}$ Resource seeking can be an important source of delay and therefore requires detailed scrutiny.

A second structural category for research are coping strategies, which are punctual strategies activated in order to cope with disease. Coping strategies usually include occasional work, child labor, borrowing money, theft, sales of food stores and productive assets, etc. ${ }^{63}$ When analyzing coping strategies, it is important to include not only tangible costs but also the capacity to activate relevant networks in asking for support from other family members, other households, patrons, the government, etc. ${ }^{64}$ To avoid the risk of exhausting these resources, ${ }^{65}$ people may opt to delay or abandon treatment, which can increase the patient's physical vulnerability if delay or the lack of adherence leads to further complications of the disease..$^{52}$

\section{Medical pluralism}

Medical pluralism ${ }^{66}$ refers to the different types of health provision that coexist in a territory and their relationships to one another. Although throughout Africa, malaria is generally considered to be the disease best treated by biomedicine, ${ }^{3}$ convulsions and chronic complications such as severe anemia and splenomegaly are treated by traditional healers, often in combination with biomedical treatments. ${ }^{3,24,39}$ To start with self-treatment at home with subsequent visits to health care professionals, and switching between different health care sectors, is common ${ }^{22,24,67}$

Kleinman ${ }^{13}$ developed the concept of Health Care System and its three sectors: i) the professional sector (e.g. biomedicine, Ayurveda, homeopathy, etc.); the folk sector (e.g. traditional and neo-traditional medicine, churches, etc.) and the popular sector (home treatment). It is important to distinguish between public and private sectors, as they can share medical paradigm, though they can be different in terms of resources, structure, praxis and institutional culture. In the PASS-model, we employ the distinction between the main categories of biomedical, traditional medicine and home treatment. Depending on the context, other categories might be preferred.

A very useful concept for understanding medical pluralism is the medical division of labor $^{68}$ i.e. which medicines are considered particularly competent for treating different symptoms and diseases. For example, in Tanzania spiritual healers are considered competent for treating witchcraft, while normal malaria, AIDS, tuberculosis, and so on, are the domain of biomedicine. Likewise, stomachache is the competence of herbalists. Some diseases can be treated by both herbalists and biomedical specialists and the actual choice will depend on other factors such as costs, the personality of the health provider, and distance. ${ }^{69}$

The role played by traditional healers cannot be minimized. In rural Africa, medical doctors are outnumbered by traditional healers. Furthermore, the traditional healers are located in places where the community has easy access. This makes them popular and readily relied on by communities. ${ }^{70}$ However, there is a risk in assuming that traditional medicine is a source of delay. Although in certain situations this may be the case, it is necessary to research and understand all therapy choices made in peoples' complete itineraries and not just the first option. ${ }^{49,71}$ For example, in Tanzania, for treating convulsions, enlarged spleen and anemia, attending a local healer did not cause delay, since the traditional treatment served to cool down the disease before taking the child to the hospital. ${ }^{30}$

\section{Conclusions}

In academic, policy and non-governmental organizations (NGO) circles, it is widely accepted that there is a compelling need to study HSB and access to care. ${ }^{72}$ The PASSmodel, originally developed for malaria, proposes an easy-to-use, hands-on tool that helps researchers in the field to identify the right variables within the broad spectrum of factors that are potentially relevant for explaining HSB and access to care. The purpose being that any researcher interested in situating health behavior in a given social, political, and economic landscape can use this tool for any health condition, in low income as well as high

Table 1. Acceptability categories for bed nets.

\begin{tabular}{lc}
$\begin{array}{lc}\text { Perceived benefits } \\
\text { Malaria prevention }\end{array}$ & Perceived risks \\
Perceived complementary benefits & Perceived inconveniences \\
Protects from insects and other animals & Heat \\
Protects from dust and dirt & Mounting is a bothersome activity \\
\hline Provides intimacy & Problems related with color symbolism \\
\hline
\end{tabular}


income countries.

The PASS-model for HSB and access to care research is a pathway model that integrates elements from other models. Founded on theory, it facilitates the formulation of questions to cover the broad array of elements that guide HSB and access to care. It is adaptable to different contexts and research questions. The PASS-model does not only list, but it also interlaces different factors and facilitates analysis of the accumulation of elements and the various logics behind HSB processes.

In order to meaningfully use this tool, the PASS-model has to be adapted to different contexts and research topics, since not all listed factors are relevant in all contexts. Depending on the intervention, disease and setting, some factors deserve more in-depth analysis while others need less emphasis. For example, adapted to malaria, the model emphasizes access to treatment for childhood malaria ${ }^{58}$ and for acceptance of intermittent preventive treatment in pregnancy (IPTp). ${ }^{52}$ The model was further adapted for prevention with insecticide-treated bed net (ITN) ${ }^{73}$ In the study of Buruli ulcer disease, ${ }^{74}$ the focus was on the costs of treatment as a major obstacle for access to care. And the model applied to HIV/AIDS stressed the multiple uses of health resources. ${ }^{69}$

Furthermore, the different factors included in the model have to be situated within the frame of specific cultures and societies. For example, access to care and resource seeking need to be understood in the context of gender and class inequalities, ${ }^{75,76}$ decision making and perceived etiology need to be considered in the wider context of worldview and dominant ideologies. Most importantly, it must be kept in mind that HSB or access to care cannot be explained by individual or detached factors.

\section{References}

1. World Health Organization. Strategic social, economic and behavioural research (SEB). Geneva: World Health Organization; 2012. Accessed: November 22, 2012. Available from: http://www.who.int/ tdr/publications/tdr-research-publications/ seb-brochure/en/index.html

2. Heggenhougen KH, Hackethal V, Vivek P. The behavioural and social aspects of malaria and its control; 2003 Accessed on: November 18, 2012. Available from: http://www.who.int/tdr/publications/tdrresearch-publications/social-aspectsmalaria-control/en/index.html

3. Williams HA, Jones $\mathrm{COH}$. A critical review of behavioral issues related to malaria control in sub-Saharan Africa: what contributions have social scientists made? Soc
Sci Med 2004;59:501-23.

4. Hausmann-Muela S, Ribera JM, Nyamongo I. Health-Seeking Behaviour and the health system response. DCPP Working Paper No. 14; 2003. Available from: www.dcp2.org/file/29/wp14.pdf

5. Lane SD. Television minidramas: social marketing and evaluation in Egypt. Med Anthropol Q 1997;11:164-82.

6. Nichter M. Social science lessons from diarrhea research and their application to ARI. Hum Organ 1993;52:53-67.

7. DiClemente RJ, Crosby RA, Kegler MC. Emerging theories in health promotion practice and research: strategies for improving public health. 1st ed. San Francisco: Jossey-Bass; 2002.

8. Conner M, Norman P. Predicting health behaviour. 2nd ed. Buckingham: Open University Press; 2005.

9. Thaddeus S, Maine D. Too far to walk: maternal mortality in context. Soc Sci Med 1994;38:1091-110.

10. Andersen R, Newman JF. Societal and individual determinants of medical care utilization in the United States. Milbank Q 1973;51:95-124.

11. Gladwin $\mathrm{CH}$, editor. Ethnographic decision tree modeling. Thousand 0aks: Sage Publications; 1989.

12. Obrist B, Iteba N, Lengeler C, et al. Access to health care in contexts of livelihood insecurity: a framework for analysis and action. PLoS Med 2007;4:e308.

13. Kleinman A. Patients and healers in the context of culture: an exploration of the borderland between anthropology, medicine, and psychiatry. Berkeley: University of California Press; 1981.

14. Agyepong IA. Malaria: ethnomedical perceptions and practice in an Adangbe farming community and implications for control. Soc Sci Med 1992;35:131-7.

15. Aikins MK, Pickering H, Greenwood BM. Attitudes to malaria, traditional practices and bednets (mosquito nets) as vector control measures: a comparative study in five west African countries. J Trop Med Hyg 1994;97:81-6.

16. Winch PJ, Makemba AM, Kamazima SR, et al. Local terminology for febrile illnesses in Bagamoyo District, Tanzania and its impact on the design of a communitybased malaria control programme. Soc Sci Med 1996;42:1057-67.

17. Ahorlu CK, Koram KA, Ahorlu C, et al. Sociocultural determinants of treatment delay for childhood malaria in southern Ghana. Trop Med Int Health 2006;11:1022-31.

18. Peeters Grietens K, Soto V, Erhart A, et al. Adherence to 7-day primaquine treatment for the radical cure of $P$. vivax in the Peruvian Amazon. Am J Trop Med Hyg 2010;82:1017-23.
19. Gessler MC, Msuya DE, Nkunya MH, et al. Traditional healers in Tanzania: the perception of malaria and its causes. J Ethnopharmacol 1995;48:119-30.

20. Matthies F. Traditional herbal antimalarials - their role and their effects in the treatment of malaria patients in rural Tanzania [PhD Thesis]. University of Basel, Faculty of Science ed.; 1998.

21. Janzen JM, Arkinstall MDW. The quest for therapy: medical pluralism in lower Zaire. Berkeley: University of California Press; 1982.

22. Muela SH, Ribera JM, Tanner M. Fake malaria and hidden parasites - the ambiguity of malaria. Anthropology \& Medicine 1998;5:43-61.

23. Evans-Pritchard EE, Gillies E. Witchcraft, oracles and magic among the Azande. Abridged. New York: 0xford University Press; 1976.

24. Hausmann Muela S, Muela Ribera J, Mushi AK, et al. Medical syncretism with reference to malaria in a Tanzanian community. Soc Sci Med 2002;55:403-13.

25. Helman CG. Culture, health and illness. London: Hodder Arnold; 2000.

26. Rubel AJ, O’Nell CW, Collado-Ardon R, et al. Susto: a folk illness. Berkeley: University of California Press; 1984.

27. Aikins MK, Pickering H, Alonso PL, et al. A malaria control trial using insecticidetreated bed nets and targeted chemoprophylaxis in a rural area of The Gambia, west Africa. 4. Perceptions of the causes of malaria and of its treatment and prevention in the study area. T Roy Soc Trop Med H 1993;87(Suppl 2):25-30.

28. Bonnet D. Représentations culturelles du paludisme chez les Moose du Burkina. [Article in French]. Ouagadougou: ORSTOM ed.; 1986. Available from: http:// www.documentation.ird.fr/hor/fdi:39222

29. Schwab M. Traditionelle und biomedizinische Malariakonzepte in der Region Dori (Burkina Faso). [Article in German]. Bern: Ethnologisches Institute ed.; 1998.

30. Hausmann-muela S, Ribera JM. Recipe knowledge: a tool for understanding some apparently irrational behaviour a,b. Anthropology \& Medicine 2003;10:87-103.

31. Desai MR, Phillips-Howard PA, Terlouw DJ, et al. Recognition of pallor associated with severe anaemia by primary caregivers in western Kenya. Trop Med Int Health 2002;7:831-9.

32. Ryan GW. What do sequential behavioral patterns suggest about the medical decision-making process? Modeling home case management of acute illnesses in a rural Cameroonian village. Soc Sci Med 1998;46:209-25.

33. Whyte SR. Questioning misfortune: the pragmatics of uncertainty in eastern 
Uganda. Cambridge: Cambridge University Press; 1998.

34. Geest S van der, Whyte SR. The context of medicines in developing countries: studies in pharmaceutical anthropology. Berlin: Springer; 1988.

35. Abraham C, Sheeran P. The health belief model. Predicting health behaviour: research and practice withsocial cognition models. 2nd ed. Buckingham: Open University Press; 2005. p. 28-80.

36. Sauerborn R, Nougtara A, Hien M, et al. Seasonal variations of household costs of illness in Burkina Faso. Soc Sci Med 1996;43:281-90.

37. Weller SC, Ruebush II TR, Klein RE. Predicting treatment-seeking behavior in guatemala: a comparison of the health services research and decision-theoretic approaches. Med Anthropol Q 1997;11:22445.

38. Garro LC. On the rationality of decisionmaking studies. 1. Decision models of treatment choice. Med Anthropol Q 1998; 12:319-40.

39. Mwenesi HA. Mothers' definition and treatment of childhood malaria on the Kenyan coast. Med Educ1994;28 (Suppl. 1): 140 .

40. Nyamongo IK. A folk model of malaria causation among the Abagusii of southwestern Kenya: implications for malaria treatment. In Nkwi PN, editor. The anthropology of Africa: challenges for the 21st century. Yaounde: ICASSRT; 2000. p. 53-61.

41. Peeters Grietens K, Xuan XN, Ribera J, et al. Social determinants of long lasting insecticidal hammock use among the Raglai ethnic minority in Vietnam: implications for forest malaria control. PLoS ONE 2012; 7:e29991.

42. Minja HD. Introducing insecticide treated mosquito nets in the Kilombero Valley (Tanzania): social and cultural dimensions. [PhD Thesis]. University of Basel, Faculty of Science ed.; 2001.

43. Winch PJ, Makemba AM, Kamazima SR, et al. Seasonal variation in the perceived risk of malaria: implications for the promotion of insecticide-impregnated bed nets. Soc Sci Med 1994;39:63-75.

44. Downie RS, Tannahill C, Tannahill A. Health promotion: models and values. Oxford: Oxford University Press; 1996.

45. Mbiti JS. African religions and philosophy. 2nd ed. Portsmouth: Heinemann; 1992.

46. Bastide R. Le principe d'individuation. Contribution à une philosophie africaine. [in French]. Colloque international du CNRS. Paris: CNRS; 1973. p. 33-43.

47. Ranger T0. Godly medicine: the ambiguities of medical mission in Southeast Tanzania, 1900-1945. Soc Sci Med-Med Anth 1981;15:261-77.

48. Janzen JM. Therapy management: con- cept, reality, process. Med Anthropol Q 1987;1:68-84.

49. Ribera JM, Hausmann-Muela S. The straw that breaks the camel's back. Redirecting health-seeking behavior studies on malaria and vulnerability. Med Anthropol Q 2011;25:103-21.

50. Muela SH, Mushi AK, Ribera JM. The paradox of the cost and affordability of traditional and government health services in Tanzania. Health Policy Plann 2000;15: 296-302.

51. Desclaux A. De la mère responsable et coupable de la maladie de son enfant. Soigner au pluriel. Essais sur le pluralisme médical. [in French]. Karthala: Paris; 1996. p. 251-79.

52. Peeters Grietens K, Gies S, Coulibaly SO, et al. Bottlenecks for high coverage of intermittent preventive treatment in pregnancy: the case of adolescent pregnancies in rural Burkina Faso. PLoS ONE 2010;5: e12013.

53. Kleinman A. Writing at the margin: discourse between anthropology and medicine. 1st ed. Berkeley: University of California Press; 1997.

54. Muela Ribera J, Peeters Grietens K, Toomer E, et al. A word of caution against the stigma trend in neglected tropical disease research and control. PLoS Negl Trop Dis 2009;3:e445.

55. Alaii JA, Hawley WA, Kolczak MS, et al. Factors affecting use of permethrin-treated bed nets during a randomized controlled trial in western Kenya. Am J Trop Med Hyg 2003;68(Suppl. 4):137-41.

56. Simons-Morton B, Haynie D, Noelke E. Social influences: the effects of socialization, selection and social normative processes on health behaviour. 2nd ed. San Francisco: Jossey-Bass; 2009.

57. Fishbein M, Ajzen I. Predicting and changing behavior: the reasoned action approach. 1st ed. Hove: Psychology Press; 2009.

58. Hausmann-Muela S. Community understanding of malaria, and treatment-seeking behaviour, in a holoendemic area of southeastern Tanzania. [PhD Thesis]. University of Basel, Faculty of Science ed.; 2000. Available from: http://edoc.unibas. ch/diss/DissB_5427

59. McLaughlin CG, Wyszewianski L. Access to care: remembering old lessons. Health Serv Res 2002;37:1441-3.

60. D’Oliveira AFPL, Diniz SG, Schraiber LB. Violence against women in health-care institutions: an emerging problem. Lancet 2002;359:1681-5.

61. Ribera JM, Hausmann-Muela S, D'Alessandro U, et al. Malaria in pregnancy: what can the social sciences contribute? PLoS Med 2007;4:e92.

62. Russell S. The economic burden of illness for households in developing countries: a review of studies focusing on malaria, tuberculosis, and human immunodeficiency virus/acquired immunodeficiency syndrome. Am J Trop Med Hyg 2004;71(Suppl. 2):147-55.

63. Sauerborn R, Adams A, Hien M. Household strategies to cope with the economic costs of illness. Soc Sci Med 1996;43:291-301.

64. Swift J. Why are rural people vulnerable to famine? IDS Bull-I Dev Stud 1989;20:8-15.

65. Chambers R. Poverty and livelihoods: whose reality counts? Environ Urban 1995; 7:173-204.

66. Leslie CM. Asian medical systems: a comparative study. New Delhi: Motilal Banarsidass Publishers; 1998.

67. Nyamongo IK. Health care switching behaviour of malaria patients in a Kenyan rural community. Soc Sci Med 2002;54: 377-86.

68. Obeysekere G. The impact of Ayurvedic ideas on the culture and the individual in Sri Lanka. In: Leslie C., editor. Asian medical systems: a comparative study. Berkeley: University of California Press; 1976. p. 201-26.

69. Muela Ribera J. Medical pluralism in Africa. Women, AIDS and access to health care in Sub-Saharan Africa: approaches from the social sciences. Medicus Mundi Catalunya ed: Barcelona; 2008. p. 105-15. Available from: http://www.sidafrica.net/ publicaciones/VITA_eng_WEB.pdf

70. Abdool KS, Ziqubu-Page T, Arendse R. Bridging the gap: potential for a health care partnership between African traditional healers and biomedical personnel in South Africa. S Afr Med J 1994;84:s1-16.

71. Savigny D de, Mayombana C, Mwageni E, et al. Care-seeking patterns for fatal malaria in Tanzania. Malaria J 2004;3:27.

72. Gilson L, Schneider H. Commentary: managing scaling up: what are the key issues? Health Policy Plann 2010;25:97-8.

73. Sangaré LR, Weiss NS, Brentlinger PE, et al. Determinants of use of insecticide treated nets for the prevention of malaria in pregnancy: Jinja, Uganda. PLoS ONE 2012;7:e39712.

74. Peeters Grietens K, Toomer E, Um Boock A, et al. What role do traditional beliefs play in treatment seeking and delay for Buruli ulcer disease? Insights from a mixed methods study in Cameroon. PLoS ONE 2012;7:e36954.

75. Ojanuga DN, Gilbert C. Women's access to health care in developing countries. Soc Sci Med. 1992;35:613-7.

76. Muela Ribera J, Hausmann S. El paludismo y otras penurias. Salud y desigualdades de género en Tanzania. [Article in Spanish]. Quaderns de l'Institut Català d'Antropologia 2006;22:139-60. 